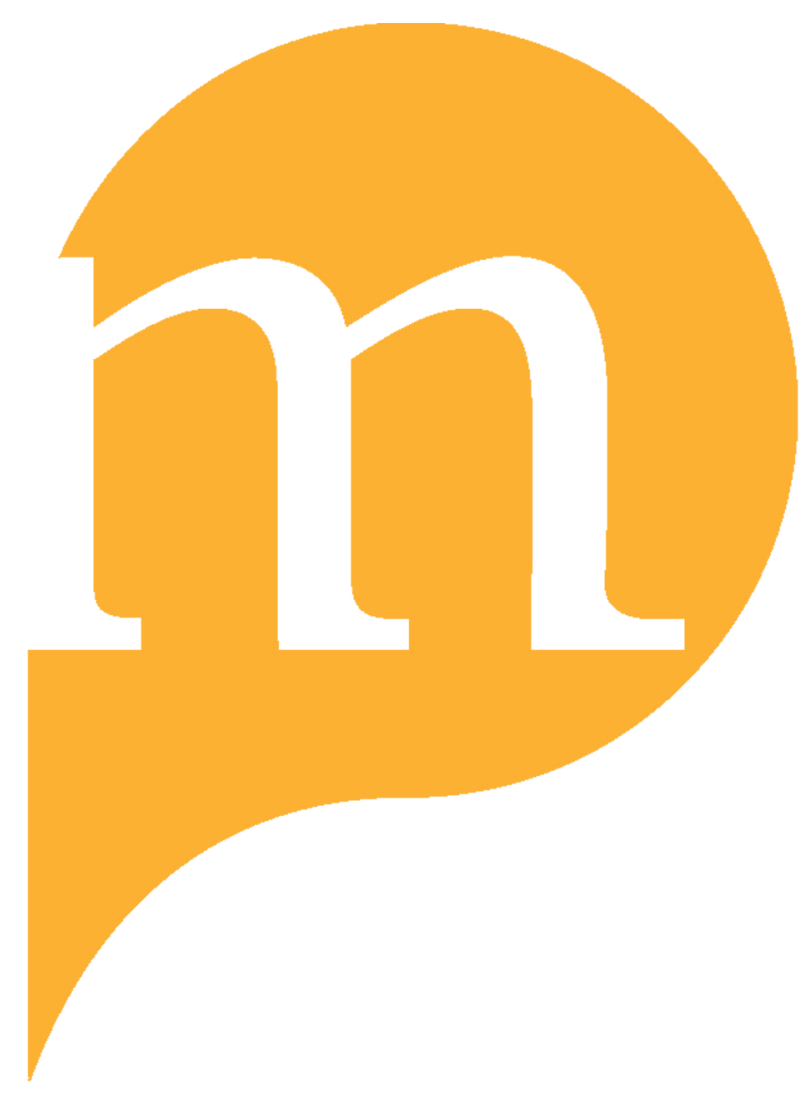

PROJECT MUSE 


\title{
Redefining Diaspora through a Phenomenology of Postmemory 1
}

\author{
Sandra So Hee Chi Kim \\ University of Southern California
}

This article seeks to intervene in the debates about the definition of diaspora by attending to the way in which it is a phenomenon, rooted in a particular kind of experience and consciousness. This approach seeks to move beyond ontological definitions based on categorical criteria toward a more phenomenological definition that can help us better understand the lived experience of diasporic subjects and the formation of diasporic communities. While these groups do not exist as entities that have some common essence or nature, I insist that they do exist phenomonologically. Rather than an objective, prescriptive definition of diaspora, this essay explores the subjective, descriptive quality of diaspora when approached from the inside, as an experience. A phenomenological approach, therefore, can rescue the term diaspora from its overextensions and case-specific limitations. A key consideration will be the role of memory in creating the phenomenon of diaspora. Diaspora must be understood as a phenomenon that emerges when displaced subjects who experience the loss of an "origin" (whether literal or symbolic) perpetuate identifications associated with those places of origin in subsequent generations through the mechanisms of postmemory.

Keywords: diaspora, postmemory, Ricoeur, memory, phenomenology

\section{Defining Diaspora}

There has been much debate over the definition of diaspora in an effort to curb the explosive proliferation of meanings it has taken on in the last couple of decades. Once its use expanded beyond its early application to "dispersed" Jewish and Armenian communities, the term diaspora evolved from being a proper noun to a common noun synonymous with "dispersion" in general. Scholars like Khachig Tölölyan (2007) have rightly called attention to how the ease with which diaspora is used as a

Sandra So Hee Chi Kim, "Redefining Diaspora through a Phenomenology of Postmemory," Diaspora 16, 3 (2007): 337-352. (C) 2013 Diaspora: a jourmal of transnational studies. 
synonym for a myriad of related phenomena blurs significant distinctions that should be addressed. What is at stake is the potential for diaspora to continue to be an enabling and productive critical term that connects histories of displacements with questions of power, identification, race/ethnicity, and citizenship (among others).

One typical approach to this problem has been to develop a list of characteristics that are intrinsic to the dynamics of diaspora and that transcend each and every individual case (Butler 2001, 89). The problem with this approach is that most existing definitions formed along these lines are too categorical and reductive. They are too often informed by teleological and idealist understandings of the nation-state as well as by an essentialist tendency to see diasporas as unitary actors and "bona fide actual entities" (Brubaker 2005, 10).

On the other end of the spectrum, postcolonial critics like Stuart Hall (1990) and James Clifford (1994) avoid a definition altogether in favor of an emphasis on the "necessary heterogeneity and diversity" (Hall 1990, 235) of diasporic identity and the hybridity, fluidity, and constantly changing nature of diasporic experience. Rogers Brubaker (2005) argues that we should think of diaspora as primarily linguistic - "an idiom, a stance, a claim" - and as such, a category of practice rather than substance (12). Stéphane Dufoix (2008) goes so far as to suggest that the term diaspora is "theoretically lifeless" and not in the least useful for any role other than as "a rallying cry" that tries to give coherence and visibility to a group (107). The problem with the kinds of definitions on this end of the spectrum is that they are so open and abstract that they lack any specificity or relevance to diaspora as an actual social phenomenon of connections between communities often born of displacement, loss, and mourning. I find Lily Cho's formulation of diaspora helpful. As she very eloquently observes, "Diaspora brings together communities not quite nation, not quite race, not quite religion, not quite homesickness, yet they still have something to do with nation, race, religion, longings for homes which may not exist. There are collectivities and communities which extend across geographical spaces and historical experiences. There are vast numbers of people who exist in one place and yet feel intimately related to another" (2007, 13; emphasis added). There are. How diasporas become indexical and observable in this way is what concerns me in this essay.

Whether too categorical or too open, a common issue is that current definitions ignore the way in which diaspora is a phenomenon and a lived experience. I agree with Lily Cho $(2007,14)$ that diasporas are "not just there," that they are not simply "collections of people" or "objects of analysis" to be identified and classified. I do, however, want to take her thesis that "diaspora is a condition of subjectivity" and push it further. Perhaps it would be more precise to say that to be diasporic is a condition of subjectivity, and that diaspora as a social phenomenon emerges from such conditions of subjectivity. In this essay I would like 
to focus on what creates both diasporic subjectivity and its passage through inter-subjectivity to the formation of "diasporas." An important concept that has not been adequately explored in this respect is that of the role of memory, and specifically postmemory.

Marianne Hirsch, in her writings on family photography and the Holocaust, uses the term postmemory to describe "the relationship of the second generation to powerful, often traumatic, experiences that preceded their births but were nevertheless transmitted to them so deeply as to seem to constitute memories in their own right" (2008, 103). The second generation cannot literally, of course, "remember" the experiences of those who came before, but postmemory describes the way in which a categorically different kind of memory is constructed by means of the stories, images, and behaviors among which the second generation grew up. Hirsch argues that "these experiences were transmitted to them so deeply and affectively as to seem to constitute memories in their own right" $(2008,106)$. Postmemory is not identical to memory: it is "post"-after, secondhand-but at the same time, it approximates memory in having a kind of affective force. Postmemory is distinguished from memory in the discontinuous subjective attachment to what one has not experienced and in the mediation of generational distance. It is different from history by the emphasis on profound personal connection to individuated histories.

Hirsch's work shows how memory and postmemory are deeply involved in subject-formation and subjectivity. She focuses on survivors of the Holocaust who have been exiled from their places of origin and for whom memory is not only an act of active recollection, but also of mourning, "mourning often tempered by anger, rage, and despair" (1997, 243). Hirsch argues that the children of exiled Holocaust survivors, although they themselves have not lived through the trauma of forced separation from home, remain deeply marked by their parents' experiences. They experience home as "always elsewhere," and their own existences as perpetually diasporic. An important thing to note is that the legacy of Holocaust survivors' traumatic experiences on the subjectivities of their children does not depend on the verbal transmission of "memories." Postmemory can be just as powerfully shaped by the absence of such speech acts, by the careful silences and nonverbal states of mourning that saturate the environment of a home. ${ }^{2}$ Eva Hoffman suggests that the "language" of the family encompasses more than the verbal: "in my home, as in so many others, the past broke through in the sounds of nightmares, the idioms of sighs and illness, of tears and acute aches that were the legacy of the damp attic and of the conditions my parents endured during their hiding" (qtd. in Hirsch 2008, 112). What Hoffman is describing is the language of the body, of symptoms that are often unconscious, that are nevertheless forcefully communicated within familial space. Other features, such as certain cultural objects (family photographs, keepsakes from the abandoned world), "Old 
World" rituals and social conventions, and the experience of a language barrier between generations, are examples of other elements in familial space that can contribute to the shaping of postmemory.

While I find Hirsch's term valuable, I find her almost exclusive application of it to the second generation limiting. Hirsch perhaps focuses on the second generation because the level of identification with the original Holocaust survivor generation is stronger than with subsequent generations. Her tendency to formulate postmemory in this way largely stems from her focus on collective trauma as the sole point of "origin" for postmemory. If we, however, attend to the phenomenon of postmemory in and of itself, apart from experiences of collective trauma (though trauma is certainly a valid and intimately related issue), we quickly see that the intergenerational transmission of memory is always happening on some level within kinship structures. Moreover, each generation, each family, and each individual experiences its own form of postmemory, which is always already marked by the previous generations' postmemory and which will also influence the generations after. The workings of postmemory can thus be used as a lens through which to analyze the effects of certain historical events or collective phenomena, whether it is the effects of the Holocaust in Hirsch's study, or the effects of displacement or migration in this one. ${ }^{3}$ But to say that postmemory is constructed out of trauma is to limit the concept too narrowly. This is especially evident when Hirsch speaks of diaspora and postmemory together. I understand statements like the following as actually reversed in logic: "[the] condition of exile from the space of identity, [the] diasporic experience, is a characteristic aspect of postmemory" (1997, 243). Postmemory is, I suggest, a characteristic aspect of diaspora and not the other way around. Again, Hirsch reverses the relation of postmemory to diaspora when she suggests that "the aesthetics of postmemory is a diasporic aesthetics of temporal and spatial exile that needs simultaneously to (re)build and to mourn" (1997, 245). The "aesthetics" of diaspora, marked by feelings of loss and processes akin to mourning, is actually born of the dynamics of postmemory. What Hirsch refers to as the "aesthetics of postmemory" is not always a "diasporic aesthetics"; a diasporic aesthetics, however, is always an aesthetics of the kind of postmemory that is marked by temporal and spatial exile. Since the workings of postmemory can occur within a sociocultural context that does not involve migration or displacement, ${ }^{4}$ it is not that postmemory is characterized in some essential way by diaspora. Rather, the phenomenon of diaspora emerges from the psychical and sociocultural dynamics of postmemory.

I want to suggest that diasporic identities are consolidated and constructed primarily via mechanisms of postmemory. What is essential in defining diaspora by way of postmemory is the emphasis within the concept of postmemory on (1) the inter/transgenerational transmission of memory and (2) the identifications forged within familial space. In 
order to grasp more deeply how displacement from a place of origin (whether literal or symbolic) affects subsequent generations, we will now turn our attention to formulating a phenomenological sketch of diasporic postmemory.

\section{Toward a Phenomenology of (Diasporic) Postmemory}

In order to appreciate the distinctive experience of postmemory, it is useful to compare and contrast it to the experience of memory. Philosopher Paul Ricoeur (2006) has contributed significantly to the development of a phenomenology of memory in his important book Memory, History, Forgetting. I will build upon his conclusions to formulate more specifically a phenomenology of postmemory, which is distinct from, yet intertwined with, the phenomenology of memory. The main differences between the experience of postmemory and the experience of memory concern (1) the subjective relationship between the objects of memory (memories) and the work of memory, (2) the role of the imagination, and (3) the significance of affect in relation to the Other.

Ricoeur relies on Edmund Husserl's phenomenological procedure (1931) in his formulation of the experience of memory. This procedure involves identifying the constitutive phases of every intentional experience, which Husserl terms noesis and noema. Noesis refers to the process of intention that assigns meaning to intentional objects, while noema stands for the intentional object itself, that is, that which is intended or meant by an act. They are related such that every noetic phase of consciousness corresponds to a noematic phase of consciousness. Ricoeur observes that for the phenomenon of memory, the noesis is the act of remembering and the noema are the memories themselves. But who is doing the remembering? While Ricoeur's discussion of the reciprocal constitution of personal and collective memory (2006, 95) complicates a simple answer to this question, the presupposition is nevertheless that the noesis-noema of memory is attached under one individual consciousness: one's memory is of one's own memories. Yet Ricoeur emphasizes, along with Maurice Halbwachs, that "one never remembers alone," that the social framework is a dimension inherent in the work of recollection. The memories the ego searches for are the result of the confluence of internal and external influences that are often imperceptible (2006, 122). I want to suggest that postmemory further complicates the mutual implication of individual and collective memory by the structural mechanism that drives it: the idea that one's past can be passed on to another. The focus is not only one's memory of one's own memories, but also one's memory of another's memories. In postmemory, the consciousnesses involved in the intentional act multiply, making the subjectivity behind the noesis and the noema plural and discontinuous.

This subjective discontinuity leads to other key differences between a phenomenology of memory and a phenomenology of postmemory, 
the role of the imagination being a fundamental one. Ricoeur traces the debate about the difference between memories and images, or memory and the imagination, back to the writings of Plato and Aristotle. For Plato, memory is fundamentally a form of re-presentation, in which faithfulness to a memory object depends on the strength of the initial impression it made. The image or icon that is formed in the representation erases the difference between the memory and its correlate. Aristotle, however, distinguishes between two kinds of memory: mnēme and anamnēsis. The former refers to passive, simple memory, which arises spontaneously in the manner of an affection (Ricoeur 2006, 17). The latter refers to recollection, which consists in an active search and an "effort to recall" $(2006,19) .{ }^{5}$ The connection between the two is the role played by temporal distance. The act of remembering only occurs after time has elapsed. Time remains the common factor to both memory as simple evocation and to recollection as action. Following Aristotle, Ricoeur argues that "the notion of temporal distance is inherent in the essence of memory and assures the distinction in principle between memory and imagination" $(2006,18)$. The temporal mark-the mark of pastness-is key to understanding the distinctiveness of memory. Memory is, more than anything else, the experience of temporal distance. However, the two extremes of the spectrum are connected. Ricoeur $(2006,52)$ quotes Bergson: "to imagine is not to remember. No doubt a recollection, as it becomes actual, tends to live in an image; but the converse is not true, and the image, pure and simple, will not be referred to the past unless, indeed, it was in the past that I sought it." Disentangling imagination from memory, then, requires focusing on the difference in intentionality: while imagination is directed toward the fantastic, the unreal, and the fictional, memory is directed toward prior reality, such that "the thing remembered" is always constituted by the temporal mark. The estimation of time intervals, whether precise or indeterminate, is part and parcel of what makes memory different from imagination.

With this schema of memory versus the imagination in mind, I understand postmemory as being something in-between: while still being directed toward a prior reality, because the subject of postmemory has not experienced that reality, the work of recalling it entails significant use of the imagination. It is from the first instance recollection, and therefore secondary in being a form of re-production; it is never primary in the sense of "simple memory" since the reference point is never to the experience of an initial perception. The reference point is, however, tied to the perception of another person's experience, and thus still grounded in a past reality. Postmemory therefore retains the object-oriented character and temporal mark of memory, but from the standpoint of another person's consciousness. The effort to recall, then, is creative; it is a practice of citation, mediation, and I would argue, imagination. 
While Ricoeur $(2006,49)$ argues that "the world of experience" and the "world of fantasy" are irreducible to one another, and that memories belong to the former, postmemory seems in fact to be a hybrid of both. With memory, one does not simply remember oneself, seeing, experiencing, learning; rather one recalls the situations in the world in which one has had such experiences. Every situation implies one's own body and the bodies of others in lived space, and the view of a world within which something has occurred. Remembering manifests the presence of the absent world, not just the experience of the prior self. Places that have been inhabited, where corporeal memory ${ }^{6}$ was practiced day in and day out, in addition to the experiences of seeing, interacting, speaking, learning, and so forth, are "memorable par excellence" (Ricoeur $2006,42)$. The places persist as inscriptions for memory and can in turn offer support for failing memory (41). But for the subject of postmemory, that "presence" of the absent world manifests itself differently than for the subject of memory. Ricoeur himself emphasizes the kinship between memories and place when he says that "memories transmitted only along the oral path fly away as do the words themselves" (2006, 41). Postmemory, however, is precisely such a form of memorial transmission that is produced along paths of communication that are detached from the places of memories. Postmemory, in fact, must imagine worlds. Diasporic postmemory in particular must actively conjure up places, situations, and bodies from which it is not only temporally discontinuous, but also spatially, culturally, and/or linguistically so. Instead of reconstructing a memory-image from "pure memory,"7 diasporic postmemory relies on a kind of analogical imaging that takes the memories communicated by another person and translates them through an existing visual archive of private and public images. This process clearly involves more than the use of the visualizing function of the imagination; it uses imagination in the way we think of the making of fiction. And yet there still exists an "objective" correlate of the experiences postmemory tries to recall, from a past that actually occurred.

Ricoeur perhaps treads onto the problematic of postmemory without naming it as such in his discussion of hallucination, memory, and history. On the one hand, Ricoeur very much pits memory against imagination, using hallucination as the example of imagination's negative effect on the processes of memory. He points out that recollection involves the construction of memory-images that refer back to prior reality, carrying "memory back . . into a region of presence similar to that of perception." While one could argue that this is a kind of use of the imagination, Ricoeur insists that it differs from the imagination's function of "derealization, [which] culminat[es] in a fiction exiled to the margins of reality" $(2006,52)$. If one were to move from pure memory to pure memory-image, Ricoeur maintains that memory then moves into the pole of hallucination, which he deems the "pitfall of the imaginary for 
memory" $(2006,53)$ in that it "constitutes a sort of weakness, a discredit, a loss of reliability for memory" $(2006,54)$. While this might be true for a single subject of memory, the memory versus imagination distinction becomes less clear-cut when we consider the subjects of diasporic postmemory who are always already searching for a prior reality that requires the active use of their faculties of imagination. "Memory is on the side of perception" (2006, 53), according to Ricoeur, but postmemory is decidedly not since it has no traffic with "pure memory"and yet postmemory retains the same thesis of reality that grounds memory.

Interestingly enough, Ricoeur acknowledges that even though hallucination is antithetical to memory as "a pathology of the imagination," it seems nonetheless related to collective memory. Drawing from the conclusions of Jean Paul Sartre's The Psychology of Imagination, Ricoeur observes that hallucination is marked by an obsession with "that which is forbidden," in which every effort "not to think about [something] anymore" is spontaneously transformed into "obsessive thinking" (Sartre qtd. in Ricoeur 2006, 54). In something of a tangent, Ricoeur makes the connection to collective memory:

Confronting the phenomenon of fascination with the forbidden object, how can we help but leap to the plane of the collective memory and evoke the sort of hauntedness, described by historians of the present day, which stigmatizes this "past that does not pass"? Hauntedness is to collective memory what hallucination is to private memory, a pathological modality of the incrustation of the past at the heart of the present. $(2006,54)$

Ricoeur dichotomizes collective memory and private memory here, but what happens when we consider postmemory, where collective memory and private memory intersect? Postmemory is at once haunted by the collective and yet undeniably individual and private. It is often characterized by a haunting and a longing for something that has been irrevocably lost (if not "forbidden").

Postmemory shares an important feature with hallucination: it uses imagination "to produce the object of one's thought, the thing one desires, in a manner that one can take possession of it" (2006, 53). However, to say that postmemory is a type of hallucination would be risible. Perhaps it would be more convincing to consider postmemory in connection to another activity that Ricoeur likens to quasi-hallucinationthe writing of history. Ricoeur does not fail to observe that, despite his schema which uncouples memory from the imagination, the writing of history employs memory and imagination together. He uses Michelet as an example of "a certain way of writing history ... in which the 'resurrection' of the past also tends to take on quasi-hallucinatory forms" and asserts that, in this way, "writing history shares the adventures of memories put-into-images under the aegis of the ostensive function of 
imagination" (2006, 54). Postmemory, like the writing of history, is the imaginative recollection of a(nother's) prior reality. This is not an empty similarity or coincidental parallel. When Ricoeur assures us that the "theory of memory passes on to the theory of history" (2006, 54), he is setting up the paradigm by which he develops an ethics of memory (which he goes into in depth in the last part of Memory, History, Forgetting). If Ricoeur is right that the theory of memory passes on to the theory of history, then postmemory is the hinge between them. Ricoeur is able to develop an ethics of memory from such a paradigm precisely because the working of postmemory implies an ethical exercise in its nature as a specific search for the truth (implied in the intentional, active search of the past) of an Other.

Postmemory is very much shaped by its production under the context of affect in relation to the Other. As we observed at the beginning of this phenomenological sketch, postmemory radically departs from the noesis-noema of memory by virtue of the subjective discontinuity between the two phases of intentionality. As such, the relationship between the subject of postmemory and the Other whose consciousness envelops the intentional object of memory is key to a phenomenological understanding of (diasporic) postmemory.

As discussed earlier, in distinguishing between the two kinds of memory, Aristotle characterizes simple memory as a pathos, as an affection, which distinguishes it from recollection, which is an action. Postmemory has characteristics of both simple memory and recollection: it is more like recollection in that it is a more laborious, effortful act, but it is like simple memory in that it can very much be characterized as an affection. The affection is different from that of simple memory, however, in that postmemory is directed not only toward the self subject of the noesis, but also toward the other subject of the noema. It involves a relational, embodied encounter with the Other that incites empathic identifications. As such, the index of postmemory, unlike memory, is "shaped more and more by affect, need, and desire as time and distance attenuate the links to authenticity and truth" (Hirsch 2008, 124). Time and distance is even further complicated and inaccessible in diasporic consciousness.

As a form of recollection, postmemory is the active search of another's past. Regarding recollection in memory, Ricoeur suggests that "the initiative of the search stems from our 'capacity for searching.' The starting point remains under the command of the explorer of the past, whether the connection that follows is the result of necessity or of habit" $(2006,18)$. This is not true of recollection in postmemory, where there is no choice for the "explorer of the past"-the past is passed onto them regardless of initiative or intentionality. What then is the "capacity for searching" for the subject of postmemory? Is there such a capacity? I would propose that there is, but that the capacity is different in an important way: it is constituted by a reliance on the one-the 
Other-who remembers. Postmemory thus intrinsically implies a relationship of trust, as one listening to the testimony of a witness. Postmemory entails a "capacity of searching" the Other, which in the intimate context of familial relations also becomes a matter of searching the self. This is especially important in diasporic consciousness, as the way in which family members have been othered in a society in which they might be marginalized for their racial features, or their cultural practices, or their lack of linguistic fluency in the dominant tongue, gets passed onto the diasporic subject through the affections of postmemory.

Emmanuel Lévinas (1979) has elaborated on the profound significance of the face-to-face encounter with the Other as the core element of intersubjective life. The other person addresses me, calls to me, simply by presenting her face to me. This lived immediacy is essentially an affective encounter that does not need language for a call-and-response dynamic between two people. Lévinas, not surprisingly, focuses on the universal "moments" of the family as constituent of both intersubjectivity and the formation of ethics. Beginning with "fecundity," in which the limits of time for the individual (one's lifespan) are extended and opened up by the child, who is both of the parent and other than the parent, the life of the family continues through interactions of election and responsibility between parents and children, and between siblings. The family in this way mediates the passage from the individual to the collective; the structure of postmemory functions within and is dependent on this familial face-to-face dynamic and, in my view, shapes the kind of intersubjectivity that leads to the phenomenological existence of groups like diasporas.

\section{The Role of Postmemory in Diasporic Consciousness and Group Formation}

How do we characterize the passage from individual diasporic consciousness to the formation of diasporic groups? Related to this question is another, more fundamental question: "is memory primordially personal or collective" (Ricoeur 2006, 93)? The response does not have to be either/or, although the tendency has been to fall on one side or the other, with Sigmund Freud perhaps being on one end and Maurice Halbwachs on the other. I follow Ricoeur, however, in the idea of a "distinct, yet reciprocal and interconnected, constitution of individual memory and collective memory" (2006, 95). The collective is already in "individual" memory from the outset. Memories are always situated with respect to other people and to places. When we look at a photograph of ourselves, it sends us back to the milieu in which we were situated at the time. The external is always present, but we tend to think of memories as essentially internal and unified only because the influence of the social setting becomes imperceptible to us. Thus the sole 
attribution of memories to the individual who remembers is a faulty claim; one never remembers alone. The social framework is a dimension inherent in the work of recollection. Alfred Schutz has argued that "the experience of others is a given as primal as the experience of the self" (qtd. in Ricoeur 2006, 130). We act with others, we affect others, and we are affected by others. Life is always in one way or another life that is lived together; subjects are from the outset members of a community or collectivity. Individuals are part of social groups with shared belief systems that frame memories and shape them into narratives.

Following Ricoeur's schema, individual consciousness necessarily involves an analogical transfer to the Other, which leads to the intersubjectivity that is ultimately the foundation for the phenomenological existence of collectives or groups like "diasporas." Husserlian phenomenology proposes that the Other is constituted from "the sphere of ownness," a reduction in which one abstracts everything in one's experience that is an experience of Otherness, leaving only what is "mine." And yet the ego forms intentionalities that transcend one's own being. The objective world is statically constituted as already finished and alien to the ego, and the possibility of experiencing the world as alien comes, first, from the possibility of experiencing the alter ego as Other: "On the one hand, it is indeed as foreign, that is as not-me, that the other is constituted, but is 'in' me that he is constituted" (qtd. in Ricoeur 2006, 118). The sphere of ownness, and the analogical apperception that follows from it, leads to what Ricoeur (improvising on Husserl's concept of "social communalization") calls the "communalization of subjective experience" $(2006,119)$. From alter egos we get a community of "Others"; and then the world as "there" for any member of this community. From this starting point with Husserl, ${ }^{9}$ Ricoeur argues that intersubjectivity bears the weight of the constitution of collective identities (like diaspora) according to the analogical transfer that Husserl ascribes to every alter ego in relation to one's own ego. This is how the first person can become the first person plural and still "retain" the features of memory: "mineness," "continuity," and "the past-future polarity." It is only by analogy -in relation to individual consciousness and its memory - that "collective memory is held to be a collection of traces left by the events that have affected the course of history of the groups concerned" $(2006,119)$. The analogical transfer allows us to extend the "mineness" of memories analogically to the idea of "our" possessing of "our" collective memories. Ricoeur shows how "this is enough to give written history a point of anchorage in the phenomenological existence of groups" (2006, 120). "Diasporas" are just such these kinds of groups, ones that exist phenomenologically in relation to a collection of traces passed on from individuals of the displaced generation to the postmemory of generations after.

Ricoeur suggests that "the level of our close relations," which he defines as "privileged others" who "approve of my existence and whose 
existence I approve of in the reciprocity and equality of esteem" (2006, 132), is an intermediate level of reference between the poles of individual memory and collective memory. Close relations occupy the middle ground between the self and the "they," and is the plane where "concrete exchanges operate between the living memory of individual persons and the public memory of the communities to which we belong" (2006, 131; emphasis added). The memory exchange that happens on the level of close relations, which he calls a "memory of a distinct kind," is in fact what I have been referring to as postmemory. I would argue that the level of familial close relations ${ }^{10}$ in particular is a crucial conduit for the formation of diasporic consciousness precisely because of the concreteness, the embodied force, of its exchanges. The phenomenon of diaspora demonstrates the production of the social bond within the framework of interactive relations in familial space.

Diaspora is only interesting as a phenomenon when collective identifications with a "homeland" are maintained by second, third, and subsequent generations. That migrants themselves invest in the preservation of a distinctive identity and community is only to be expected (Brubaker 2005, 7). What characterizes and explains the passage from dislocated subjects to diaspora, I argue, are the processes of postmemory and intersubjectivity, in which the familial structure of inheritance is significant. The family becomes a crucial unit of transmission of an embodied form of memory that encompasses bodily and affective connections. For memory studies scholar Aleida Assman (qtd. in Hirsch 2008, 110 ), the family is the privileged site of memorial transmission because memories are first and foremost linked between individuals. "Group memory" begins from the point of familial transfer of embodied experience to the next generation. Various forms of public memory, on the other hand (national, political, cultural, archival, etc.), are primarily mediated not through embodied practice but instead through symbolic systems.

Critical race scholar Sara Ahmed (2007) similarly emphasizes the importance of the familial space in producing phenomenological orientations and subjectivity in her essay, "A Phenomenology of Whiteness." Building from Marx's insight that although human beings "make their own history, [they] do not make it as they please," Ahmed suggests that that process of "making" is delimited by the conditions they inherit from the past. She observes that "if the conditions in which we live are inherited from the past, they are 'passed down' not only in blood and genes, but also through the work or labor of generations" $(2007,154)$. This inheritance would include the social, cultural, and psychical orientations that a person encounters from the moment of entry into the world as a dependent child, not to mention the work of memory that is performed in these familial spaces. Ahmed suggests that orientations put certain things within reach, such as "styles, capacities, aspirations, techniques, habits" in addition to physical objects $(2007,154)$. Though 
her essay refers to the orientation of "whiteness," we can also see diasporic postmemory as creating another such orientation.

One way in which diasporic postmemory orients a subject is through its function as a form of family resemblance. Ahmed notes how whiteness becomes a form of family resemblance, which explains how race has been understood through familial metaphors: "Race in this model 'extends' the family form; other members of the race are 'like a family,' just as the family is defined in racial terms" $(2007,154)$. This relates to diasporic consciousness in that the same extension of the family metaphor occurs in the related discourse of the nation; both race and nation are deeply entangled with diasporic discourse. The analogy that members of the nation or race are "like a family" works powerfully to produce not only a particular rendering of race and/or nation, but also a particular rendering of family that is based on likeness as a sign of inheritance. The discourse of "family resemblance," in Ahmed's view, has a powerful function as a legislative device. She reflects on the saying "like two peas in a pod":

Anyone who has shelled peas would know of course that peas are not only alike and that seeing them as being alike is already to overlook some important differences. But it's the pod and not the peas that interests me here. This saying suggests for me that likeness is an effect of the proximity of shared residence. This is not just an argument about nurture over nature (that the pod is a nurturing device), as this way of thinking relies on an overly simple logic of causality (the pod causes the peas). Rather the very proximity of pea-to-pea, as well as the intimacy of the dwelling, which surrounds them like a skin, shapes the very form of the peas. Likeness is not then 'in' the peas, let alone 'in' the pod, but is an effect of their contiguity, of how they are touched by each other and envelop each other. (Ahmed 2007, 155)

The familial is like the "pod," as a shared space of dwelling, in which things are shaped by their proximity to other things. Bodies come to be seen alike, as for instance sharing a race, or a "homeland," as a "characteristic." Such "characteristics" are an effect of proximities where certain memories, experiences, and "truths" are already in place. Ahmed suggests that such proximities are inherited, which means that "[the] past that is 'behind' our arrival restricts as well as enables human action: if we are shaped by 'what' we come into contact with, then we are also shaped by what we inherit, which de-limits the objects that we might come into contact with" $(2007,155)$. Diasporic consciousness forms out of the "foreignness" of the multiple worlds that one has inherited, such that the world that the diasporic subject inhabits is perpetually haunted by the absence of another, distant world. For the second generation of self-identified "diaspora," the world they inherit is one in which their parents experienced varying types and degrees of alienation, loss, and 
nostalgia for a "homeland." But the chain of inheritance often does not stop with the second generation. The transfer of diasporic postmemory and identification to subsequent generations can occur vis-à-vis a variety of "inheritances" of proximity, such as the effects of racial and ethnic categorizations circulating in larger society, marginalization as an "Other," social and cultural practices of "boundary maintenance," identification with already-formed parental identities/ideologies, the affect and practices of long-distance nationalism, and so forth, that are passed onto the subject of postmemory. Diasporic postmemory reproduces and evolves when buttressed by reinforcements of external exclusion as well as internal "likeness." The passage from postmemory to diaspora happens when an individual's consciousness coheres to cultures, values, bodies, and places from the familial past as properties of itself. Diasporic identification thus is "an effect of what coheres, rather than the origin of coherence" (Ahmed 2007, 159; emphasis added).

\section{Diaspora, a Becoming}

Diaspora is better understood phenomenologically than ontologically. Diaspora does not refer to a static, homogeneous entity bound together by some common essence or purity. Nor does it refer to a mere flourish of language, strategic practice, or oppositional stance employed by the marginalized and disenfranchised. Diaspora instead refers to a certain experience, or as Stuart Hall describes it, a becoming:

Cultural identity . . . is a matter of "becoming" as well as of "being". It belongs to the future as much as to the past. It is not something which already exists, transcending place, time, history, and culture. Cultural identities come from somewhere, have histories. But, like everything which is historical, they undergo constant transformation. Far from being eternally fixed in some essentialized past, they are subject to the continuous "play" of history, culture, and power . . . identities are the names we give to the different ways we are positioned by, and position ourselves within, the narratives of the past. $(1990,225)$

A definition of diaspora that emphasizes the experience of diasporadiaspora as becoming - allows us to move away from universalizing generalizations and the pitfalls of essentialism and assimilationist teleologism. Anchoring it to a phenomenology of postmemory compels us to attend to how collective histories and individual narratives of the past produce diasporic experience in complex relation to the relentless play of history, culture, and power in larger society. As such, redefining diaspora through a phenomenology of postmemory can help us account more adequately for the realms of heterogeneity, hybridity, discontinuity, and evolution in diasporic experience without denying its "reality." Diaspora is real. 


\section{Redefining Diaspora through a Phenomenology of Postmemory}

\section{Notes}

1. The author thanks Bruce Smith and Khachig Tölölyan for their very helpful feedback on this manuscript.

2. Nadine Fresco conducted a series of interviews with others of her generation whose parents never spoke of their lives in their home countries or of their experiences of war. She argues that these repressed stories nevertheless shaped them as a diaspora des cendres ["diaspora of the ashes"]. Fresco referred to this experience as "absent memory," which Hirsch recasts as postmemory, emphasizing that such a memory is not "empty" or "absent," but full, present, and invested in its own right (Hirsch 1997, 243-4).

3. Of course, these cases are not mutually exclusive. One can be traumatized by forceful displacement, for instance. Or a collective trauma can involve the massive displacement of a group of people, the Holocaust being an obvious example. Hirsch's own work constantly links the experience of trauma with exile/diaspora in postmemory. However, in my view, it is important to separate out the terms clearly before analyzing them together.

4. A case in point is how postmemory has been usefully applied to the aftermath of the "Dirty War" in Argentina. See Nouzeilles 2005 and Kaiser 2006 for examples.

5. Husserl made a similar distinction: primary memory (retention) versus secondary memory (reproduction). Primary memory as retention is "not now"; it is necessary that a corresponding perception precede the retention. But retention hangs onto the perception of the moment. The perception is "just past"; so retention is a temporal extension of that experience. Secondary memory, however, entails reproduction, which assumes that the primary memory of a temporal object has "disappeared" and that it comes back. It is still different from imagination because of the positional dimension of recollection: "Recollection ... posits what is reproduced and in this positing gives it a position in relation to the actually present now and to the sphere of the original temporal field to which the recollection itself belongs." The reproduction then is now, but it coincides with the real past (Ricoeur 2006, 31-6).

6. Corporeal memory refers to habits of the body, or sensual knowledge, enacted repeatedly in lived space. It bears similarities to Pierre Bourdieu's concept of habitus in its emphasis on embodiment and unconscious inculcation.

7. "Pure memory" refers to memory that has not yet been put into images. It aligns with the unconscious and is an existence "comparable to that $[\mathrm{sic}]$ we attribute to external things when we do not perceive them” (Ricoeur 2006, 51, 431).

8. Although this word is problematic in that it strikes of a kind of biologism, a paradigm of the "familial" can be extended to analogous relationships of both formal and informal "adoption," as well as, to a lesser degree, broader social relations dispersed according to multiple orders of belonging.

9. Ricoeur is careful, however, to distance himself from the transcendental idealism implied in Husserl's method. He asks, "in order to reach the notion of common experience, must we begin with the idea of ownness, pass through the experience of the other, and finally proceed to a third operation, said to the communalization of subjective experience? Is this chain truly irreversible? Is it not the speculative presupposition of transcendental idealism that imposes this irreversibility, rather than any constraint characteristic of phenomenological description?" (2006, 119). In my view, a non-transcendental idealist approach to Husserl's ideas leaves open the possibility that the chain is not irreversible nor even necessarily a "chain" with discrete or sequential phases. Simultaneity and mutual constitution would not change the thesis of analogical transfer. Husserl's schema is thus valuable as a heuristic for understanding intersubjectivity.

10. See note 8 for a caveat concerning the concept of the "familial." 


\section{Diaspora 16:3 2007}

\section{References}

Ahmed, Sara. 2007. “A Phenomenology of Whiteness.” Feminist Theory 8 (2): 149-68. http://dx.doi.org/ 10.1177/1464700107078139

Brubaker, Rogers. 2005. “The 'Diaspora' Diaspora.” Ethnic and Racial Studies 28 (1): 1-19.

Butler, Kim D. 2001. "Defining Diaspora, Refining a Discourse.” Diaspora 10 (2): 189-219. http://dx.doi. org/10.1353/dsp.2011.0014

Cho, Lily. 2007. "The Turn to Diaspora.” Topia: Canadian Journal of Cultural Studies 17: 11-30.

Clifford, James. 1994. "Diasporas." Cultural Anthropology 9 (3): 302-38. http://dx.doi.org/10.1525/ can.1994.9.3.02a00040

Dufoix, Stéphane. 2008. Diasporas. Berkeley: University of California Press. http://dx.doi.org/10.1525/ california/9780520253599.001.0001

Hall, Stuart. 1990. “Cultural Identity and Diaspora.” In Identity: Community, Culture, Difference, ed. Jonathan Rutherford, 222-37. London: Lawrence \& Wishart. http://www.lwbooks.co.uk/ebooks/identity.pdf

Hirsch, Marianne. 1997. Family Frames: Photography, Narrative, and Postmemory. Cambridge, MA: Harvard University Press.

Hirsch, Marianne. 2008. "The Generation of Postmemory." Poetics Today 29 (1): 103-28. http://dx.doi. org/10.1215/03335372-2007-019

Husserl, Edmund. 1931. Ideas: General Introduction to Pure Phenomenology, trans. W.R. Boyce Gibson. London: Allen \& Unwin.

Kaiser, Susana. 2006. Postmemories of Terror: A New Generation Copes with the Legacy of the 'Dirty War'. New York: Palgrave Macmillan.

Lévinas, Emmanuel. 1979. Totality and Infinity: An Essay on Exteriority. Vol. 1. The Hague: M. Nijhoff. http://dx.doi.org/10.1007/978-94-009-9342-6

Nouzeilles, Gabriela. 2005. "Postmemory Cinema and the Future of the Past in Albertina Carri's Los Rubios." Journal of Latin American Cultural Studies 14 (3): 263-78. http://dx.doi.org/10.1080/ 13569320500382500

Ricoeur, Paul. 2006. Memory, History, Forgetting, trans. Kathleen Blamey and David Pellauer. Chicago: University of Chicago Press.

Tölölyan, Khachig. 2007. "The Contemporary Discourse of Diaspora Studies." Comparative Studies of South Asia, Africa and the Middle East 27 (3): 647-55. http://dx.doi.org/10.1215/1089201x-2007-040 